\title{
Projects to encourage female students in STEM areas
}

\begin{abstract}
Ana Isabel Allueva-Pinilla', José Luis Alejandre-Marco', María Teresa LozanoAlbalate $^{2}$, Raquel Trillo-Lado ${ }^{3}$, Sergio Ilarri-Artigas ${ }^{3}$, Carlos Sánchez-Azqueta ${ }^{4}$, Lorena Fuentes-Broto ${ }^{5}$, Susana Bayarri-Fernández ${ }^{6}$, Concepción Aldea-Chagoyen ${ }^{4}$

${ }^{1}$ Department of Applied Mathematics, Universidad de Zaragoza, Spain, ${ }^{2}$ Centro Universitario de la Defensa, Universidad de Zaragoza, Spain, ${ }^{3}$ Department of Computing and Systems Engineering, Universidad de Zaragoza, Spain, ${ }^{4}$ Department of Electronic Engineering and Communications, Universidad de Zaragoza, Spain, ${ }^{5}$ Department of Pharmacology and Physiology, Universidad de Zaragoza, Spain, ${ }^{6}$ Department of Animal Production and Food Science, Universidad de Zaragoza, Spain.
\end{abstract}

\begin{abstract}
Today, the number of female students that enrol in degrees related to Science, Technology, Engineering and Mathematics (STEM) areas is quite low. So, numerous initiatives have arisen to promote these degrees and encourage female students in these areas. In this context, the EuLES Network (u-Learning Environments in Higher Education), an interdisciplinary network created in 2010 at the University of Zaragoza (Spain) to foster research, interaction, cooperation and transfer of knowledge and technologies related to learning and open education, has developed two projects oriented to High School Students: "WikinformáticA! en Aragon" and "Women in STEM by EuLES". WikinformáticA! en Aragón is a competition for student groups in which they develop a wiki on prominent women in the history of Information and Communication Technology (ICT). The objective is the visibility of women involved in technology. The purpose of the Women in STEM project is to offer testimonies of women in Science, Technology, Engineering and Mathematics to encourage scientific vocations, especially in young people and girls. The project consists of conducting video interviews of women who work or study in these disciplines. All the videos, along with a short biography, are posted on the web.
\end{abstract}

Keywords: ICT; collaborative work; gender equality; wikis; EuLES network; STEM. 


\section{Introduction and motivation}

The EuLES Network (Allueva-Pinilla, Alejandre-Marco, Trillo-Lado, \& Lozano-Albalate, 2017; EuLES, 2011) is an interdisciplinary educational research network in uLearning environments in higher education. It has been recognized as an Interdisciplinary Network of the University of Zaragoza, within its incentive programme of educational innovation, since 2010.

The objectives of the EuLES Network are the promotion of the interaction and cooperation, transfer of knowledge and technology, and the exchange of experiences and resources among its members and the rest of the educational community, in relation to uLearning environments at a higher education level. We consider the network as a wide model where the different evolutions of the learning process combined with the latest technology trends are combined. Thus, some trends considered are: bLearning models (Blended Learning), eLearning, mLearning (Mobile Learning), Web 2.0 and the concept of ubiquity, that allows us to develop the teaching-learning process at any time, place and situation.

The purpose of the EuLES Network is to contribute to the development of training activities, exchanges, mobility and scientific interaction, while increasing the visibility of the participant institutions, and thus also to contribute to collaboratively create and share knowledge to improve the teaching quality.

For several years, a fundamental concern of this Network has been the role and presence of women in the education environment, and particularly in STEM (Science, Technology, Engineering and Maths) areas. This vision is consistent with one of the objectives presented in Article 23 of the Organic Act 3/2007 for effective equality between women and men: "The education system will include among its aims the teaching of respect for fundamental rights and freedoms and equal rights and opportunities for women and men. Likewise, the principles defining education system quality will include the elimination of obstacles that thwart the effective equality between women and men and the furtherance of full equality between the two sexes."

The acronym STEM specifically refers to Science, Technology, Engineering and Mathematics, but there is no standard definition for what constitutes a STEM job. In these fields, there is also an agreement to include other positions, such as educators, managers, technicians, healthcare professionals, and social scientists (Beede et al., 2011). On the other hand, there are variations in the identification of academic disciplines included in this acronym. The National Science Foundation (NSF) uses the term Science and Engineering to include agricultural, biological, and computer Sciences; atmospheric, earth, and ocean Sciences; Mathematics and Statistics; Astronomy; Chemistry; Physics; aerospace, chemical, civil, electrical, industrial, materials, and mechanical Engineering; social Sciences, and Psychology (Johnson, 2011; Rodríguez, 2016). 
The focus of the EuLES Network is placed on the most global meaning of the STEM term. Accordingly, we try to encourage the visibility of women in all the related areas. For example, the "Women in STEM by EuLES" project consists of conducting video interviews of women who work or study in STEM-related disciplines. Similarly, the "WikinformáticA! en Aragon” project implies the development of a contest among teams of high school students that are in charge of developing wikis to help visibilize women with prominent roles in STEM areas. The main motivation for these projects is that there is still a very significant gender gap in STEM studies, at Spanish Universities in general, and particularly at our university, the University of Zaragoza.

Table 1 shows the evolution of new enrollees in scientific-technical studies and Physics degree in the Spanish university system and also the percent of women, from information drawn from official sources. Overall, the percentage of women enrolled in Science, Mathematics or Engineering careers is around 30\% in Spanish universities (National Science Foundation \& National Center for Science and Engineering Statistics, 2017). This global data, is already significantly unequal, but there are also cases and degrees where the percentage of women enrolled is even lower. In a recent study (Allueva-Pinilla et al., 2018), authors of this paper analyzed the current situation of the University of Zaragoza in relation to the STEM areas. So, it is really worrying.

Table 1. Evolution of new enrollees in scientific-technical studies and Physics degree and percent of women.

\begin{tabular}{cccccc}
\hline $\begin{array}{c}\text { Academic } \\
\text { year }\end{array}$ & $\begin{array}{c}\text { All degrees } \\
\text { and } \\
\text { universities }\end{array}$ & $\begin{array}{c}\text { Scientific- } \\
\text { technical } \\
\text { studies }\end{array}$ & $\begin{array}{c}\text { Women in scientific- } \\
\text { technical studies } \\
\text { (in percent) }\end{array}$ & $\begin{array}{c}\text { Physics } \\
\text { degree }\end{array}$ & $\begin{array}{c}\text { Women in } \\
\text { Physics degree } \\
\text { (in percent) }\end{array}$ \\
\hline $2013-2014$ & 382060 & 94609 & $28.9 \%$ & 2916 & $25.7 \%$ \\
$2014-2015$ & 356447 & 90166 & $29.5 \%$ & 3023 & $25.0 \%$ \\
$2015-2016$ & 345835 & 82505 & $30.0 \%$ & 2871 & $26.6 \%$ \\
$2016-2017$ & 340988 & 80104 & $30.2 \%$ & 2901 & $24.9 \%$ \\
\hline $2017-2018$ & 340274 & 79614 & $30.6 \%$ & 2943 & $28.5 \%$ \\
\hline
\end{tabular}

Source: Own elaboration based on information from INE (Spanish National Institute of Statistics) and Ministerio de Educación, Cultura y Deporte (Ministry of Education, Culture and Sport, Spain). 
According to data from the Equality Observatory (Observatory of Gender Equality \& Vicerectorate of Culture and Social Projection of the University of Zaragoza, 2017), in Sciences there are $50 \%$ of female students, but only 28\% in the Physics Degree. The data is much worse in Engineering and Architecture, where, in the whole of the macro area, only a scant $21 \%$ is reached. But if we carry out an analysis by degrees, the data get much worse: in Electronics and Automation Engineering it falls to 18\%, in Mechanical Engineering to 15\%, in Electrical Engineering to 14\%, in Mechatronic Engineering and Informatics Engineering it does not even reach $10 \%$ (9.9\% and 9.8\%, respectively), and finally, in Industrial Organisational Engineering, it falls to a very low 6\%. These values are really low, but the current trends are not promising either: if we analyze the evolution in Engineering studies during the the last ten years, we see a decline with a loss of more than $5 \%$ in the percentage of female students.

Figure 1 shows the distribution of graduate students at the University of Zaragoza by branch of knowledge and sex (Observatory of Gender Equality \& Vice-rectorate of Culture and Social Projection of the University of Zaragoza, 2017). There is a reduction in the percentages of women graduates in all macro areas. It is highlighted that the gender gap is increasing in Engineering and Architecture.

- Women Men

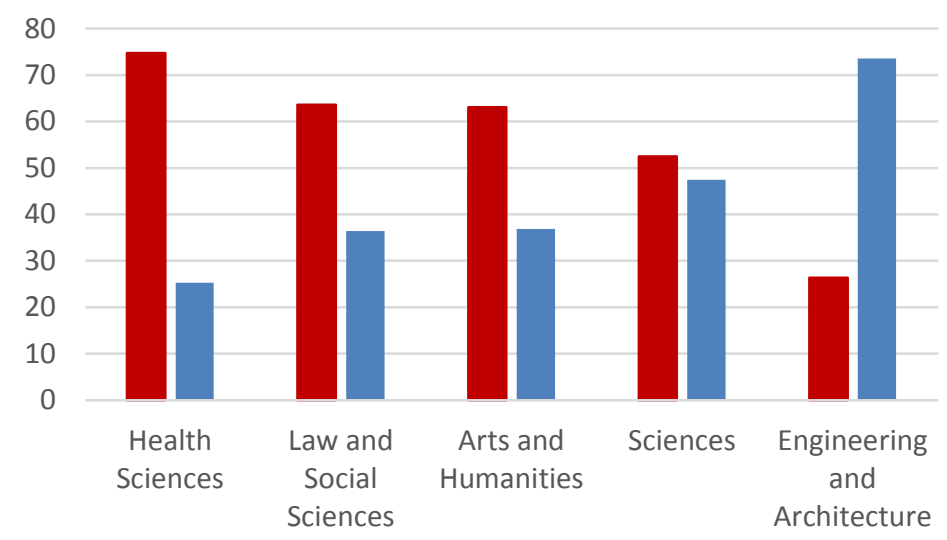

Figure 1. Distribution (in percent) of graduated students at the University of Zaragoza by branch of knowledge and sex. Academic year 2015/2016. Source: Observatory of Gender Equality (2017).

On the other hand, there are disciplines in which the number of female students is higher than that of men, as in the case of health studies, where it exceeds $70 \%$, or as it happens with some degrees such as Nursing, where $80 \%$ of the students are women. But, what happens next? In these areas, as in the others, positions of responsibility in scientific research or in the business field are not held by women. As an example, the data by sex on 
the number of Full Professors and Associate Professors (or lower academic ranks), obtained by querying the transparency portal of the University of Zaragoza (University of Zaragoza, 2018), offer proof of this.

\section{WikinformaticA! en Aragón Project}

WikinformaticA! en Aragón 2018 (EuLES, 2015; Lozano Albalate, Trillo-Lado, Villarroya-Gaudó, Allueva, \& Cerezo, 2015) is a contest where teams of students from high school and last courses of primary education make Wikis about technologists or scientists related to Information and Communication Technologies (ICT). In this contest (organized by several members of different groups from the University of Zaragoza: Departamento de Informática e Ingeniería de Sistemas -DIIS- of the Universidad de Zaragoza, Asociación de Mujeres Investigadoras y Tecnólogas -AMIT- and Red EuLES -Entornos uLearning en Educación Superior-), the potential of the Wikis is used to promote collaborative work, the use of tools for the creation of Wikis, and the publication of reliable Web content. Besides, this contest also aims to visualize the role of women in the development of Information Technologies and the Communication by making visible relevant women in the ICT world, in general, and women related to ICT who have had some kind of relationship with the University of Zaragoza, in particular. In this way, we want to contribute to provide an early positive experience in the use of technology and decrease the imbalance in the presence of women and men in Internet content, in general, and in Wikipedia in particular.

The teams of students that participate in the contest have to find out the name of certain relevant women in the field of Information and Communication Technologies (ICT) from different clues. After that, they must create articles in Wiki format dedicated to these women. Therefore, the objectives for a team of students, can be divided into technological (facilitating the use of tools and making visible different contributions to technology) and promoting gender equality (making visible the role of relevant women in the ICT world and encouraging reflection on the presence of women in technology), in both cases from education and development.

In more detail, the objectives we proposed when defining this contest were the following:

- $\quad$ Promote the use of Wikis and collaborative work among participating students.

- Give the opportunity to students to participate in a project, learning different technologies related to the search of information and publication of content in networks.

- Visualize the role of women in the development of Information and Communication Technologies (ICT), especially that of young researchers and entrepreneurs who collaborate actively with the University of Zaragoza. 
- Encourage participants, especially students, to become Wikipedia editors (given that currently, less than $15 \%$ of Wikipedia's editors - the largest encyclopedia most consulted today - are women), showing them to make edits and publications in a collaborative way using Wiki tools is a simple task and can lead to quality work.

To achieve the objectives in the contest, students must create teams composed of a number of persons between 3 and 8. Because most of the participating teams are formed by adolescents, and taking into account the current problems of legislation related to personal data and privacy, it was decided that the teams were led by a teacher (or supervisor). In this way, the organization of the contest only required the data of the teacher in order to allow a team of students to register in and participate in the contest. In addition, the teacher acts as a supervisor of the student team and as a intermediary in communication with the organization.

The edition of the contest "WikinformáticA! in Aragón" in 2018 was launched in September and ended on December 20. More than 700 students from different schools organized in 135 teams signed up. Besides, all of them finished their work on time. Finally, four prizes were given to the best works.

\section{Women in STEM by EuLES Project}

Women in STEM by EuLES is a recent project and is still under development. This project started in 2018 in order to collaborate in the celebration of the International Day of Women and Girls in Science, that is celebrated on February 11.

The purpose of this project is to offer testimonies of women in STEM areas, as well as other resources developed by the EuLES Network to encourage scientific vocations, especially in young people and girls.

A detailed description of this project can be found in Allueva el al (Allueva-Pinilla et al., 2018). Briefly, our research methodology in this research project consists of searching and contacting scientific women or female professionals and students in order to conduct video interviews, editing and publishing the recorded videos, and writing the biographies of the women interviewed. All the videos have been made by the authors and the tool used for recording and editing has been ScreenCast-O-Matic. In this way, one of the main tasks of the project consists of conducting video interviews of women who work or study in these disciplines. The videos are freely available in the YouTube channel of the EuLES Network and also in a specific portal, Women in STEM, in blog format (EuLES, 2017) organized and classified by themes. 
Our intention with this project has been to provide a vehicle by which the voices of scientific and professional women could be heard more, reaching girls and young students who have to face an election about their future studies.

The interviews in this project have focused on prominent women in STEM areas but also on women who are starting their careers, considering academic / research, professional, and even political fields, as well as Master or $\mathrm{PhD}$ students. In the interviews, all the women speak of their life experience, of the peers they have had, and of the difficulties they have encountered in their professional career, but also of the kindnesses and satisfactions that their work has given them.

\section{Conclusions}

In this paper, we have presented two projects developed with the goal of encouraging the participation of women in STEM areas. To do this, both projects make explicit the key role played by women in science and technology.

The possibility to see and hear testimonies from women working in STEM areas allows vocations to be generated in young students, which has motivated our work with the "Women in STEM by EuLES" project. The experiences reported by the women interviewed show the difficulties they have encountered in their field of work, but they also emphasize the changes that are taking place in recent years in favor of gender equality, as well as their full satisfaction for having chosen to study in any of the STEM areas.

The high number of people that have participated in the WikinformáticA! en Aragon contest has helped to promote the role of women in new technologies, thus achieving the main objective of this project. This contest has had great diffusion in the media, press, radio and television. Moreover, it has aroused great interest among secondary education centers. Many of these centers request information about the contest even before its annual call.

The projects presented in this paper not only promote the role of women in STEM areas. Besides, they bring middle school students closer to the university and promote the incorporation of students, especially women, into the first courses of teaching in scientific and technical areas. For this reason, we will continue to work in the organization of the next edition of the WikinformáticA! en Aragon contest as well as recording, editing and visualizing testimonies of women in STEM areas.

\section{Acknowledgements}

This work was supported by the Universidad de Zaragoza (Spain) [PIIDUZ_18_331]. 


\section{References}

Allueva-Pinilla, A., Alejandre-Marco, J., Trillo-Lado, R., \& Lozano-Albalate, M. (2017). EuLES Network: An initiative to foster innovation and ubiquitous-Learning on Higher Education. In D. Remenyi (Ed.), The e-Learning Excellence Awards 2017. An Anthology of Case Histories: Academic Conferences and Publishing International Limited.

Allueva-Pinilla, A., Alejandre-Marco, J., Trillo-Lado, R., Lozano-Albalate, M., AldeaChagoyen, C., Álvarez-Lanzarote, I., . . . Gimeno-Gasca, C. (2018). Women in STEM by EuLES: a project to promote scientific vocations in girls. Paper presented at the ICERI 2018 Proceedings. doi: 10.21125/iceri.2018.1773

Beede, A., Tiffany, J., Langdon, D., McKittrick, G., B., K., \& Doms, M. (2011). Women in STEM: A Gender Gap to Innovation. Economics and Statistics Administration (Issue Brief 04-11). doi:10.2139/ssrn.1964782

EuLES. (2011). Red EuLES web page. Retrieved from http://eules.org/

EuLES. (2015). WikinformáticA! en Aragón Retrieved from http://wikinformatica.eules.org/

EuLES. (2017). Women in STEM. Retrieved from http://micro.eules.org/

Johnson, D. (2011). Women of Color in Science, Technology, Engineering, and Mathematics (STEM). New directions for Institutional Research, 152. doi:10.10002/ir410

Lozano Albalate, M. T., Trillo-Lado, R., Villarroya-Gaudó, M., Allueva, A., \& Cerezo, E. (2015). An ICT experience in Computer Women Role promotion: WikinformáticA! in Aragón: Promoting the use of Wiki tools and visualizing the role of women in ICT. Paper presented at the XVI International Conference on Human Computer Interaction. doi: 10.1145/2829875.2829901

National Science Foundation, \& National Center for Science and Engineering Statistics. (2017). Women, Minorities, and Persons with Disabilities in Science and Engineering. Special Report NSF 17-310. Arlington, VA. Retrieved from https://www.nsf.gov/statistics/2017/nsf17310/

Observatory of Gender Equality \& Vice-rectorate of Culture and Social Projection of the University of Zaragoza. (2017). La igualdad de género en la Universidad de Zaragoza. Diagnóstico 2015/2016. Zaragoza, Spain Retrieved from https://observatorioigualdad.unizar.es/sites/observatorioigualdad.unizar.es/files/users/ob sigu/diagnostico_15-16.pdf

Rodríguez, A. P. (2016). Científicas en cifras 2015. Estadísticas e indicadores de la (des)igualdad de género en la formación y profesión científica. Retrieved from http://www.ciencia.gob.es/stfls/MICINN/Ministerio/FICHEROS/Informe_Cientificas_e n_Cifras_2015_con_Anexo.pdf

University of Zaragoza. (2018). Transparency Portal of the University of Zaragoza. Retrieved January 31, 2019, from https://portaltransparencia.unizar.es/ 